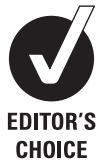

1Department of Medical and Health Sciences, Linköping University, Linköping, Sweden ${ }^{2}$ Chelsea and Westminster Hospital, Imperial College, London, UK ${ }^{3}$ London University, London, UK

\section{Correspondence to} Jan Ekstrand, Department of Medical and Health Sciences, Linköping University, Linkoping, Sweden; jan.ekstrand@telia.com

Received 3 May 2011 Accepted 20 October 2011 Published Online First 5 December 2011

\title{
Hamstring muscle injuries in professional football: the correlation of MRI findings with return to play
}

\author{
Jan Ekstrand, ${ }^{1}$ Jeremiah C Healy, ${ }^{2}$ Markus Waldén, ${ }^{1}$ Justin C Lee, ${ }^{2}$ \\ Bryan English, ${ }^{3}$ Martin Hägglund ${ }^{1}$
}

\begin{abstract}
Background Hamstring injury is the single most common injury in professional football. MRI is commonly used to confirm the diagnosis and provide a prognosis of lay-off time.

Objective To evaluate the use of MRI as a prognostic tool for lay-off after hamstring injuries in professional football players and to study the association between MRI findings and injury circumstances.

Methods Prospective cohort study where 23 European professional teams, were followed between 2007 and 2011. Team medical staffs recorded individual player exposure and time-loss injuries. Radiological grading was performed using a modified Peetrons classification into four grades where grades 2 and 3 represent fibre disruption.
\end{abstract}

Results In total, 516 hamstring injuries occurred and $58 \%$ of these were examined by MRI. Thirteen per cent were grade 0 injuries, $57 \%$ grade 1, 27\% of grade 2 and $3 \%$ of grade 3 . Grade 0 and 1 injuries accounted for $56 \%$ (2141/3830 days) of the total lay-off. The layoff time differed between all four radiological grades of injury $(8 \pm 3,17 \pm 10,22 \pm 11$ and $73 \pm 60$ days, $p<0.0001)$. Eighty-three per cent of injuries affected the biceps femoris while $11 \%$ and $5 \%$ occurred to the semimembranosus and semitendinosus, respectively. Re-injuries ( $N=34 / 207)$ constituted $16 \%$ of injuries. All re-injuries occurred to the biceps femoris.

Conclusion MRI can be helpful in verifying the diagnosis of a hamstring injury and to prognosticate layoff time. Radiological grading is associated with lay-off times after injury. Seventy per cent of hamstring injuries seen in professional football are of radiological grade 0 or 1, meaning no signs of fibre disruption on MRI, but still cause the majority of absence days.

\section{INTRODUCTION}

Muscle injuries are common in football. ${ }^{1-15}$ A recent study on male professional footballers showed that muscle injuries represent more than $30 \%$ of all injuries and cause about one quarter of total injury absence. ${ }^{4}$ Over $90 \%$ of muscle injuries affected the four major muscle groups of the lower extremity: hamstrings, adductors, quadriceps and gastrocnemius. ${ }^{4}$ Injury to the hamstring muscle group is reported to be the most common injury subtype representing $12 \%$ of all injuries. ${ }^{4}$ This means that a professional male football team with 25 players in the squad have about five hamstring injuries each season, equivalent to more than 80 lost football days. ${ }^{4}$

When an injury has occurred, the medical staff faces pressure to return the player to training and matches as soon as possible. ${ }^{16}$ The diagnosis and prognosis of muscular injuries is normally mainly based on clinical findings, but radiological methods such as MRI or ultrasound (US) are commonly used as complementary examinations in order to confirm a diagnosis and to provide a prognosis of lay-off times. ${ }^{16-21}$ Recent studies of Australian Rules football players with hamstring injuries have indicated that lay-off could be related to MRI findings such as the longitudinal length or volume of the injury. ${ }^{16-19} 21-23$

However, Australian Rules football is different from soccer, and caution should be employed when transferring knowledge from one sport to another, as mechanisms for hamstring injuries might differ between sports. ${ }^{1620}$

Furthermore, muscle injuries are a heterogeneous group of different injury types, locations, severities and sizes, and this makes prognoses about healing time and rehabilitation difficult. ${ }^{4} 1024$

The main objective of this prospective study was to evaluate the use of MRI as a prognostic tool for lay-off time after hamstring injuries on professional football players. A further aim was to investigate the use of MRI in hamstring injuries in elite level football teams and to study the association between MRI findings and injury circumstances. Our hypothesis was that the grading of injuries using MRI is associated with lay-off time from football.

\section{MATERIALS AND METHODS}

\section{Study population}

A prospective cohort study of men's professional football in Europe has been carried out since 2001, the Union of European Football Associations (UEFA) Champions League (UCL) study. ${ }^{3}$ For the purpose of this substudy, 23 European professional teams (816 players) were followed over two to four seasons between July 2007 and April 2011. All contracted players in the first teams were invited to participate in the study.

\section{Study design and definitions}

The full methodology and the validation of the study design are reported elsewhere. ${ }^{25}$ The study design followed the consensus on definitions and data collection procedures in studies of football injuries. $^{2526}$ An overview of the general definitions is seen in table 1. Specifically for this study, a hamstring injury was defined as 'a traumatic distraction or overuse injury to the hamstring muscle leading to a player being unable to fully participate in training or match play'. ${ }^{4}$ Structural 
disorders such as total and partial muscle ruptures, as well as functional disorders such as fatigue-induced, spine-related or neuromuscular muscle disorders were included while contusions, haematomas, tendon ruptures and chronic tendinopathies were excluded.

\section{Data collection}

Player baseline data were collected once yearly at the start of the season. Individual player exposure in training and matches was registered by the clubs on a standard exposure form to be sent to the study group on a monthly basis. The team medical staffs recorded injuries on a standard injury form that was sent to the study group each month. The injury form provided information about the diagnosis, nature and circumstances of injury occurrence. All injuries resulting in a player being unable to fully participate in training or match play (ie, timeloss injuries) were recorded, and the player was considered injured until the team medical staff allowed full participation in training and availability for match selection. All injuries were followed until the final day of rehabilitation.

\section{MRI}

From the 23 teams involved in the UCL study, 15 (65\%) agreed to participate in a discussion about MRI of thigh muscle injuries. A questionnaire was sent to these clubs in February 2007, and agreement was reached concerning the use of MRI for inclusion in this study. For the purpose of this study, the clubs were instructed to perform the initial MRI examination within 24-48 h of the injury event. The MRI machine should not be older than 5 years and have a field strength of at least 1.5 T. The minimum MR sequences should include axial and coronal planes using T1, T2 with fat saturation, and/or Short Tau Inversion Recovery (STIR) sequences. An MRI Thigh Injury Report Form was created with information about date of imaging, name of radiologist evaluating the images, MR sequences used, muscles involved and severity of injury. If more than one muscle was injured, the muscle with the most extensive pathology was denoted as the primary muscle involved, and assessment criteria were taken for that particular muscle.

For severity classification, a modification of Peetrons classification ${ }^{27}$ was used with the following grading system: grade 0 negative MRI without any visible pathology, grade 1 oedema but no architectural distortion, grade 2 architectural disruption indicating partial tear and grade 3 total muscle or tendon rupture. All radiologists used the same standard evaluation protocol. Nine of the teams used PACSMail (www.sybermedica. com) to send their MRIs for online review by two independent radiologists (J.H. and J.L) who were unaware of clinical details other than the suggested hamstring injury. Copies of scans and associated reports from the nine teams using PACSMail were then sent electronically to the UEFA injury surveillance study group. The other six teams had the paper-based MRI forms filled in by the consultant radiologist for the club and these were sent to the study group by mail.

\section{Analyses}

Analysis of variance with Bonferroni post hoc test was used for between-group comparisons of lay-off time. Association between categorical variables was measured with Pearson's $\chi^{2}$ test or Fisher's exact test. Bonferroni correction was used for multiple pairwise comparisons. The significance level was set at $p<0.05$. All statistical analyses were made in IBM SPSS Statistics 19.0. The study design underwent an ethical review and was approved by the UEFA Football Development Division and the Medical Committee.

\section{RESULTS}

\section{Examination procedure}

Of the 516 hamstring injuries recorded during the study period, 299 (58\%) were examined by MRI and 118 (40\%) of these also had concomitant initial US. One hundred and fifty-two injuries (29\%) were examined by initial US only without MRI, and 65 $(13 \%)$ were examined clinically without the use of any imaging. MRI forms for 207 of the 299 MRI examinations $(69 \%)$ were received (figure 1); $140 \mathrm{MRIs}$ (68\%) from nine clubs were examined by the two independent radiologists while $67 \mathrm{MRIs}$ $(32 \%)$ were examined by radiologists from six different clubs. Only 207 hamstring injuries with completed MRI forms are included in the following results.

\section{Radiological grades of injury and lay-off time}

Twenty-seven of the 207 (13\%) injuries were radiological grade $0,118(57 \%)$ were of grade 1, $56(27 \%)$ of grade 2 and $6(3 \%)$ were of grade 3 (figure 1). Grade 0 injuries accounted for $5 \%$ (207 days) of total absence (3830 days) due to hamstring injuries, compared with 51\% (1934 days), 33\% (1250 days) and 11\%

Table 1 Operational definitions

\begin{tabular}{|c|c|}
\hline Training session & Team training that involved physical activity under the supervision of the coaching staff \\
\hline Match & Competitive or friendly match against another team \\
\hline Injury & $\begin{array}{l}\text { Injury resulting from playing football and leading to a player being unable to fully participate in future } \\
\text { training or match play (ie, time-loss injury) }\end{array}$ \\
\hline Hamstring injury & $\begin{array}{l}\text { A traumatic distraction or overuse injury to the hamstring muscle leading to a player being unable to } \\
\text { fully participate in training or match play }\end{array}$ \\
\hline Rehabilitation & $\begin{array}{l}\text { A player was considered injured until team medical staff allowed full participation in training and } \\
\text { availability for match selection }\end{array}$ \\
\hline Lay-off & Number of days until the player resumed full team training \\
\hline Re-injury & $\begin{array}{l}\text { Injury of the same type and at the same site as an index injury occurring no more than } 2 \text { months after a } \\
\text { player's return to full participation from the index injury }\end{array}$ \\
\hline Minimal injury & Injury causing absence of $1-3$ days from training and match play \\
\hline Mild injury & Injury causing absence of $4-7$ days from training and match play \\
\hline Moderate injury & Injury causing absence of 8-28 days from training and match play \\
\hline Severe injury & Injury causing absence of over 28 days from training and match play \\
\hline Traumatic injury & Injury with sudden onset and known cause \\
\hline Overuse injury & Injury with insidious onset and no known trauma \\
\hline
\end{tabular}




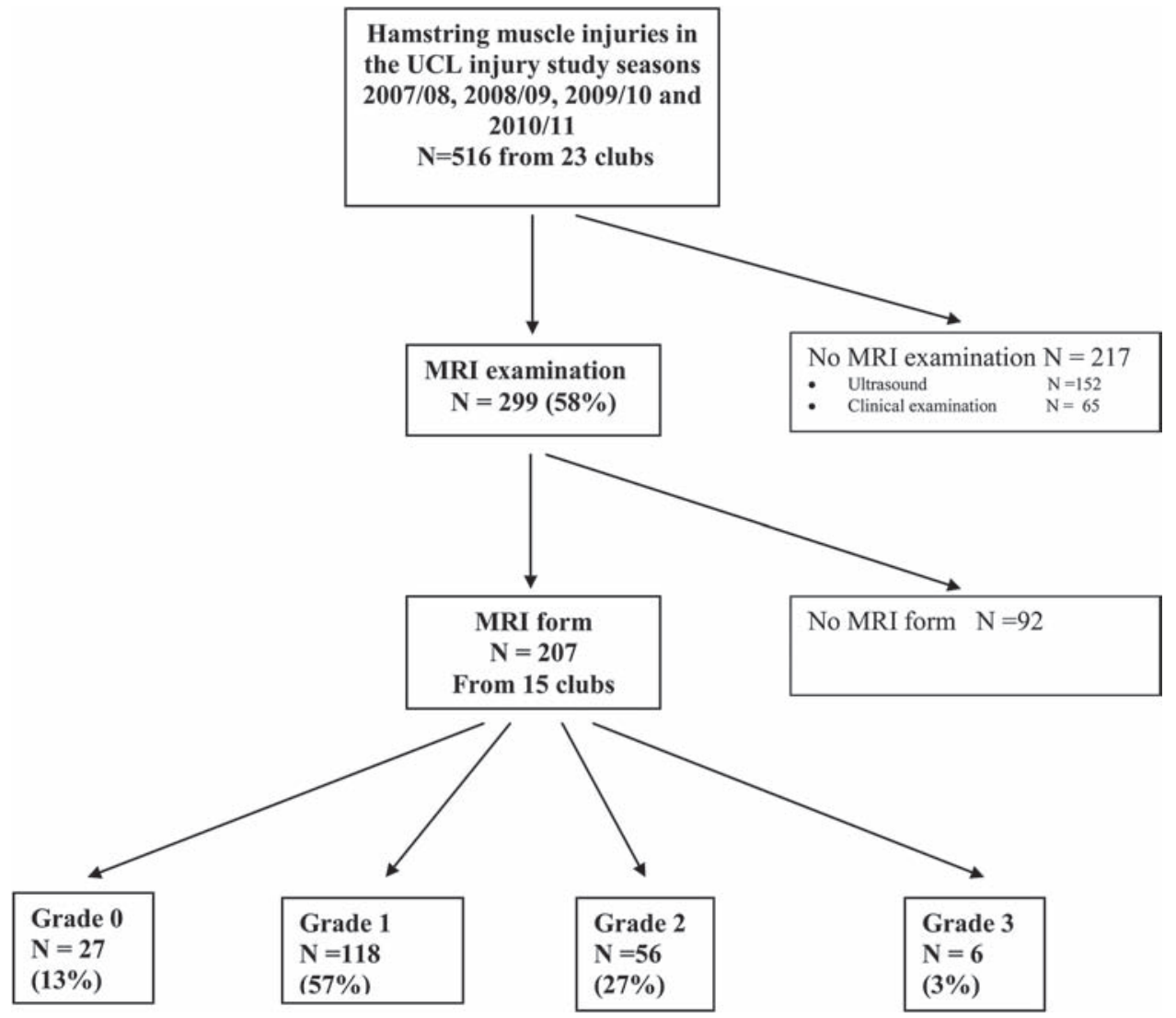

Figure 1 Flowchart of hamstring muscle injuries in the UEFA Champions League injury study seasons 2007/08, 2008/09, 2009/10 and 2010/11.

(439 days) for grades 1, 2 and 3, respectively. The lay-off time from football differed significantly between the four grades of injury $(8 \pm 3,17 \pm 10,22 \pm 11$ and $73 \pm 60$ days for grades $0,1,2$ and 3 respectively, $\mathrm{p}<0.001)$. When performing pairwise comparisons, the differences were significant between all pairs except between grades 1 and $2(p=0.053)$. However, the figures for grade 3 are less robust since it is a small group with a large variation of absence days. As seen in table 2, there was a clear association between radiological grades and clinical severity as measured by the absence days from training sessions and match-play.

\section{Muscles involved}

From the 180 injuries with some muscle pathology visible on MRI (grades 1-3), 151 (84\%) affected the biceps femoris (BF) muscle while 20 (11\%) and 9 (5\%) occurred to the semimembranosus (SM) and semitendinosus (ST) muscles. There was no significant difference in lay-off time for injuries to the three

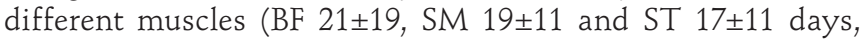
respectively, $\mathrm{p}=0.79$ ) nor was there any difference concerning distribution in radiological grading $(p=0.46)$.

\section{Circumstances of injury}

Seventy per cent (117/167, information missing for 40 of the 207 injuries) of the hamstring injuries occurred during sprinting or high-speed running. The proportion of running/sprinting injuries was similar among the different radiological grades $(\mathrm{p}=0.44)$. Other mechanisms were overuse and stretching/ sliding (each $5 \%$ ), shooting and twisting/turning (each $4 \%$ ), passing and jumping (each $2 \%$ ). When categorising injuries as traumatic or overuse, the latter ones dominated among grade 0 injuries (69\%) compared with $31 \%, 30 \%$ and $36 \%$ in grades $1-3(p<0.001, p=0.001$ and $p=0.102$, respectively). Almost all muscle injuries were non-contact in nature (95\%).

\section{Leg dominance}

Fifty-five per cent of the hamstring injuries affected the preferred kicking leg (BF 51\%, SM 67\% and ST 50\%, p=0.68). There was no difference in lay-off time between injuries to the kicking leg compared with the supporting leg $(17 \pm 14$ vs $22 \pm 25$ days, $p=0.13)$.

\section{Re-injuries}

Re-injuries constituted 16\% (34/207) of all hamstring injuries with no significant difference in rates between different radiological grades $(p=0.35)$ (table 2$)$. All 30 re-injuries with pathology on MRI (grades $1-3$ ) occurred to the biceps femoris and none of them to the semimembranosus or semitendinous muscles. There was no significant difference in lay-off times between index injuries and re-injuries $(18 \pm 18$ vs $18 \pm 11$ days, $\mathrm{p}=0.98)$. None of the six grade 3 injuries were re-injuries.

\section{DISCUSSION}

A main finding in this study was that $70 \%$ of hamstring injuries seen in professional football show no signs of fibre disruption on MRI. Still, these mild injuries represent more than half of the lay-off due to injury. Another important finding was that radiological grading was closely associated with lay-off times and might be useful to prognosticate absence.

\section{The majority of hamstring injuries are examined by MRI}

The majority of hamstring injuries occurring to players from European high-level professional football clubs were examined 
Table 2 Associations between radiological grades and clinical severity, lay-off time, muscles involved, etiology and recurrence

\begin{tabular}{|c|c|c|c|c|c|}
\hline & Total & Grade 0 & Grade 1 & Grade 2 & Grade 3 \\
\hline Injuries & 207 & $27(13 \%)$ & $118(57 \%)$ & $56(27 \%)$ & $6(3 \%)$ \\
\hline \multicolumn{6}{|l|}{ Clinical severity } \\
\hline Minimal & $5(2 \%)$ & $1(4 \%)$ & $4(3 \%)$ & 0 & 0 \\
\hline Mild & $29(14 \%)$ & $12(44 \%)$ & $13(11 \%)$ & $4(7 \%)$ & 0 \\
\hline Moderate & $143(69 \%)$ & $14(52 \%)$ & $89(75 \%)$ & $38(68 \%)$ & $2(33 \%)$ \\
\hline Severe & $30(15 \%)$ & 0 & $12(10 \%)$ & $14(25 \%)$ & $4(67 \%)$ \\
\hline Lay-off time (days) ${ }^{*}$ & $19 \pm 17$ & $8 \pm 3$ & $17 \pm 10$ & $22 \pm 11$ & $73 \pm 60$ \\
\hline \multicolumn{6}{|l|}{ Muscles involved } \\
\hline Biceps femoris & $150(84 \%)$ & & $101(86 \%)$ & $45(81 \%)$ & $5(83 \%)$ \\
\hline Semimembranosus & $20(11 \%)$ & & $12(10 \%)$ & $8(14 \%)$ & $1(17 \%)$ \\
\hline Semitendinosus & $9(5 \%)$ & & $5(4 \%)$ & $3(5 \%)$ & 0 \\
\hline \multicolumn{6}{|l|}{ Aetiology } \\
\hline Trauma & $130(64 \%)$ & $8(31 \%)$ & $79(69 \%)$ & $39(70 \%)$ & $4(67 \%)$ \\
\hline Overuse & $72(36 \%)$ & $18(69 \%)$ & $35(31 \%)$ & 17 (30\%) & $2(33 \%)$ \\
\hline Recurrence & $34(16 \%)$ & $2(7 \%)$ & $20(17 \%)$ & $12(21 \%)$ & 0 \\
\hline
\end{tabular}

Radiological grades were classified according to Peetrons ${ }^{27}$ : grade 0 negative MRI without any visible pathology, grade 1 oedema but no architectural distortion, grade 2 architectural disruption indicating partial tear and grade 3 total muscle or tendon rupture. Clinical severity was classified according to the football consensus ${ }^{26}$ : minimal (causing absence of $1-3$ days), mild (absence 4-7 days), moderate (absence 8-28 days) and severe (absence $>28$ days).

*Values are mean \pm SD.

by MRI or US or with a combination of these examinations. As always, the clinical examination is the base for diagnosis, but at the professional level different sorts of imaging are frequently used to enhance the quality of the diagnosis in order to better prognosticate healing time and lay-off from football. MRI has been the preferred modality in recent years and has offered a highly detailed imaging analysis of the extent of injury. ${ }^{1618-2028}$

\section{Most hamstring injuries have no signs of muscle fibre disruption}

Two of three hamstring injuries were grade 0 or 1 injuries, showing no signs of muscle fibre disruption on MRI. Still, these injuries caused more than half of the absence days. This means that from a club's perspective, these injuries represent a significant problem due to their high incidence, even if most hamstring injuries have a favourable prognosis and are effectively handled conservatively. ${ }^{24}$ Surgical repair is normally reserved for total ruptures, such as avulsion injuries, but these injuries are rarely seen in football, representing only a few per cent of all hamstring injuries as shown in this study.

\section{Radiological grading relates to lay-off}

The ability to predict lay-off is very important for the injured player as well as the coaching staff. ${ }^{18}$ Another main finding of this study is therefore that radiological grades are highly associated with lay-off time from football. It seems logical that radiological severity is correlated to clinical severity, thus indicating that an MRI examination done 24-48 h after a hamstring injury could provide information about what absence to be expected. Several studies from Australian Rules football ${ }^{16-19} 21-23$ have shown the possibility to use MRI to prognosticate lay-off time after hamstring injury. Schneider-Kolsky et al ${ }^{19}$ compared MRI (with radiologists blinded to clinical data) and clinical assessment of acute hamstring injuries and found both methods to be useful as a predictor for the duration of rehabilitation required.

However, muscle injuries are a heterogeneous group and the need for classification and subgrouping of muscle injuries have been emphasised. ${ }^{410}$ Ekstrand et al have recently shown that more than $90 \%$ of all muscle injuries in male elite footballers affect four muscle groups (hamstrings, quadriceps, adductors and calf muscles), but injuries to different muscle groups behave differently. If the aim is to prognosticate absence due to injuries, a further subgrouping into severity grades is necessary since the absence differs significantly between different radiological grades. As suggested by Gibbs et a ${ }^{18}$ in their studies of hamstring injuries in Australian Rules football, further subgrouping into injury type, intramuscular location and dimension of pathology might be of additional value in prognosticating absence. In this ongoing study, these qualities are measured, but (due to the necessity of subgrouping into muscle groups and grades) the numbers of each subgroup are still small and further data are needed for safer statements.

The importance of imaging has increased, as not all causes of posterior thigh pain are the result of a hamstring muscle fibre strain. ${ }^{15} 24$ We found $27(13 \%)$ grade 0 injuries with a mean absence of 8 days. Several studies have demonstrated that a negative MRI finding in the context of clinically suspected hamstring strain is associated with shorter recovery time. ${ }^{16-19} 2123$ As such, these clinically diagnosed hamstring injuries with a negative MRI appear to have a good prognosis. The actual cause of posterior thigh injury where MRI shows no pathology is unclear. It is possible that these injuries are below the sensitivity of MRI detection and are subtle muscle injuries. ${ }^{29}$ Another explanation is that such athletes may have an alternative diagnosis such as back-related problem, neural tension or muscle spasm. ${ }^{10} 16$

\section{The majority of hamstring strains affect the biceps femoris muscle}

In our 180 injuries with pathology on MRI, we found that $84 \%$ affected the BF, $11 \%$ the SM and 5\% the ST. Our findings are consistent with previous studies by Koulouris et al, ${ }^{16}$ who analysed MRIs of 31 hamstring injuries in Australian football players and found $84 \%$ injuries to the BF, $10 \%$ to the SM and $6 \%$ to the ST. 
In accordance with the findings of Slavotinek et a l $^{21}$ in Australian Rules football, we found no relation between the specific muscle involved and lay-off time.

\section{Running/sprinting most common mechanism}

It is well established that hamstring muscle injuries are common in sports characterised by high-velocity sprinting 15 30-32 or multidirectional acceleration. ${ }^{32}$ Similar to the study by Woods et al, ${ }^{15}$ our study shows that the majority of hamstring injuries occurred during running or sprinting. Eccentric overloading at the end of the swing phase has been suggested as a possible mechanism behind hamstring injuries. ${ }^{30}{ }^{32-34}$ Fatigue might be another important factor; it has previously been shown that muscle injuries occur more frequently towards the end of each half. ${ }^{345}$ In a laboratory study of male professional football players, Grieg et a ${ }^{\beta 6}$ showed that the eccentric hamstrings' strength decreased over time and, in particular, after the half-time interval. Fatigue might also alter the neuromuscular activity in the hamstrings, as shown by Pinniger et al. ${ }^{37}$

\section{Re-injuries only to biceps femoris}

Recurrent hamstring muscle injuries are common and previous injury is an important risk factor for new hamstring injury. ${ }^{15} 2338-41$ In football, recurrence rates of $12-25 \%$ has previously been reported, ${ }^{11}{ }^{15}$ but these studies have limitations such as small material, no exposure data or different definitions of a re-injury. In this study, re-injuries constituted $16 \%$ of all hamstring injuries with no significant difference in injury rates between different radiological grades. However, 30 re-injuries occurred to the BF muscle and none of them to ST or SM, a finding that needs to be further explored. Previous studies of re-injuries in general have shown that re-injuries cause longer absence than non-re-injuries. ${ }^{3}{ }^{413}$ In this study, however, no difference was found in lay-off time between reinjury and index injury, possibly indicating that top-level clubs in Europe have greater medical support, providing more individualised rehabilitation for injured players. ${ }^{4}$ One could also speculate whether the frequently used radiological examinations for diagnostics and return-to-play decisions could help to reduce the re-injury rate. ${ }^{4}$

\section{Strengths and limitations}

An obvious strength of this study is its design, with a homogeneous group of male professional footballers followed prospectively with a standardised methodology that complies with the international consensus agreements on procedures for epidemiological studies of football injuries. ${ }^{25}{ }^{26}$ Further, the number of players included and number of MRI examinations are substantially larger compared with previous studies evaluating the association between hamstring injuries and MRI findings. ${ }^{16-19} 21-23$

A limitation is that muscle injury constitute a heterogeneous group including all types of muscle injuries, structural (partial or total ruptures) as well as functional (fatigue induced, spine-related or neuromuscular muscle disorders, etc). ${ }^{4} 10$ Furthermore, the material includes muscle injuries of different severities, of different extramuscular and intramuscular locations and of different sizes. ${ }^{410}$ Next, MRIs were examined by several radiologists from different countries. Even if an agreement about how and when the MRIs should be executed and even if a standard MRI form was used, the inter-observer reliability between the different radiologists is unknown. Our study population was limited to male professional football

\section{What is already known on this topic?}

- Hamstring injury is the most common injury in professional football.

- Most of the hamstring injuries occur to biceps femoris.

\section{What this study adds}

- MRI can be helpful in verifying the diagnosis of a hamstring injury and also to prognosticate lay-off time.

- Radiological grading is associated with lay-off times after injury.

- Seventy per cent of hamstring injuries seen in professional football show no signs of fibre disruption on MRI, but still cause the majority of absence days.

players and might therefore not necessarily reflect the injury characteristics of a more general population or other levels of play. Although the use of imaging is frequently used to plan and assist rehabilitation of professional football players, an algorith $m$ that integrates clinical and imaging information into a management plan remains to be established and tested. ${ }^{20}$

As a conclusion, this study shows that MRI can be helpful in verifying the diagnosis of a hamstring injury and also to prognosticate lay-off time. Radiological grading is associated with lay-off times after injury. Seventy per cent of hamstring injuries seen in professional football show no signs of fibre disruption on MRI (radiological grade 0 or 1 injuries), but still cause the majority of absence days.

Acknowledgements The authors wish to thank the participating clubs, medical staffs and players. A special thanks to the contact persons in clubs that have sent us MRIs by PACSMail: Edwin Goedhart (AFC Ajax), Markus Braun (BV Borussia Dortmund), David Wales (Arsenal FC), Alex Nieper (Chelsea FC), Francesco Benazzo, Franco Combi and Giorgio Panico, (FC Internazionale Milano), Nelson Puga (FC Porto), Cees-Rein van den Hoogenband and Luc van Agt (PSV Eindhoven), Paco Biosca and Viktor Kirilenko (Shakhtar Donetsk). The statistical advice of Henrik Magnusson (Msc) is also gratefully acknowledged.

Funding UEFA, Swedish Centre for Research in sport and Praktikertjänst AB. Competing interests None.

Patient consent Obtained.

Ethics approval UEFA Football Division and UEFA Medical Committee.

Provenance and peer review Not commissioned; externally peer reviewed.

\section{REFERENCES}

1. Árnason Á, Gudmundsson Á, Dahl HA, et al. Soccer injuries in Iceland. Scand J Med Sci Sports 1996;6:40-5.

2. Ekstrand J, Gillquist J. Soccer injuries and their mechanisms: a prospective study. Med Sci Sports Exerc 1983;15:267-70.

3. Ekstrand J, Hägglund M, Waldén M. Injury incidence and injury patterns in professional football: the UEFA injury study. Br J Sports Med 2011;45:553-8.

4. Ekstrand $\mathbf{J}$, Hägglund $\mathrm{M}$, Waldén $\mathrm{M}$. Epidemiology of muscle injuries in professional football (soccer). Am J Sports Med 2011;39:1226-32.

5. Ekstrand J, Timpka T, Hägglund M. Risk of injury in elite football played on artificial turf versus natural grass: a prospective two-cohort study. Br J Sports Med 2006;40:975-80.

6. Hägglund $\mathbf{M}$, Waldén $\mathbf{M}$, Ekstrand J. Injury incidence and distribution in elite football-a prospective study of the Danish and the Swedish top divisions. Scand J Med Sci Sports 2005;15:21-8.

7. Hägglund $\mathbf{M}$, Waldén $\mathbf{M}$, Ekstrand J. Injuries among male and female elite football players. Scand J Med Sci Sports 2009;19:819-27. 
8. Inklaar H. Soccer injuries. I: Incidence and severity. Sports Med 1994;18:55-73.

9. Junge A, Dvorak J, Graf-Baumann T, et al. Football injuries during FIFA tournaments and the Olympic games, 1998-2001: development and implementation of an injury-reporting system. Am J Sports Med 2004;32:80S-9S.

10. Müller-Wohlfahrt H, Ueblacker P, Hänsel L. Muske/verletzungen im sport. Stuttgart Georg Thieme Verlag KG 2010.

11. Petersen J, Thorborg K, Nielsen MB, et al. Acute hamstring injuries in Danish elite football: a 12-month prospective registration study among 374 players. Scand J Med Sci Sports 2010;20:588-92.

12. Waldén $\mathbf{M}$, Hägglund $M$, Ekstrand J. UEFA Champions League study: a prospective study of injuries in professional football during the 2001-2002 season. Br J Sports Med 2005;39:542-6.

13. Waldén M, Hägglund M, Ekstrand J. Injuries in Swedish elite football—a prospective study on injury definitions, risk for injury and injury pattern during 2001. Scand J Med Sci Sports 2005;15:118-25

14. Volpi P, Melegati G, Tornese D, et al. Muscle strains in soccer: a five-year survey of an Italian major league team. Knee Surg Sports Traumatol Arthrosc 2004;12:482-5

15. Woods C, Hawkins RD, Maltby S, et al. The Football Association Medical Research Programme: an audit of injuries in professional football-analysis of hamstring injuries. Br J Sports Med 2004;38:36-41.

16. Koulouris G, Connell DA, Brukner $P$, et al. Magnetic resonance imaging parameters for assessing risk of recurrent hamstring injuries in elite athletes. Am J Sports Med 2007;35:1500-6.

17. Connell DA, Schneider-Kolsky ME, Hoving JL, et al. Longitudinal study comparing sonographic and MRI assessments of acute and healing hamstring injuries. AJR Am J Roentgenol 2004;183:975-84.

18. Gibbs NJ, Cross TM, Cameron M, et al. The accuracy of MRI in predicting recovery and recurrence of acute grade one hamstring muscle strains within the same season in Australian Rules football players. J Sci Med Sport 2004:7:248-58.

19. Schneider-Kolsky ME, Hoving JL, Warren P, et al. A comparison between clinical assessment and magnetic resonance imaging of acute hamstring injuries. Am J Sports Med 2006;34:1008-15.

20. Slavotinek JP. Muscle injury: the role of imaging in prognostic assignment and monitoring of muscle repair. Semin Musculoskelet Radiol 2010;14:194-200.

21. Slavotinek JP, Verrall GM, Fon GT. Hamstring injury in athletes: using MR imaging measurements to compare extent of muscle injury with amount of time lost from competition. AJR Am J Roentgenol 2002;179:1621-8.

22. Verrall GM, Slavotinek JP, Barnes PG, et al. Assessment of physical examination and magnetic resonance imaging findings of hamstring injury as predictors for recurrent injury. J Orthop Sports Phys Ther 2006:36:215-24.
23. Verrall GM, Slavotinek JP, Barnes PG, et al. Clinical risk factors for hamstring muscle strain injury: a prospective study with correlation of injury by magnetic resonance imaging. Br J Sports Med 2001;35:435-9; discussion 440.

24. Koulouris G, Connell D. Imaging of hamstring injuries: therapeutic implications. Eur Radiol 2006;16:1478-87.

25. Hägglund $\mathbf{M}$, Waldén $M$, Bahr R, et al. Methods for epidemiological study of injuries to professional football players: developing the UEFA model. Br J Sports Med 2005;39:340-6.

26. Fuller CW, Ekstrand J, Junge A, et al. Consensus statement on injury definitions and data collection procedures in studies of football (soccer) injuries. Br J Sports Med 2006;40:193-201.

27. Peetrons P. Ultrasound of muscles. Eur Radio/ 2002:12:35-43.

28. Megliola A, Eutropi F, Scorzelli A, et al. Ultrasound and magnetic resonance imaging in sports-related muscle injuries. Radiol Med 2006;111:836-45.

29. Verrall GM, Kalairajah Y, Slavotinek JP, et al. Assessment of player performance following return to sport after hamstring muscle strain injury. J Sci Med Sport 2006;9:87-90

30. Arnason A, Andersen TE, Holme l, et al. Prevention of hamstring strains in elite soccer: an intervention study. Scand J Med Sci Sports 2008;18:40-8.

31. Askling $\mathbf{C M}$, Tengvar M, Saartok T, et al. Acute first-time hamstring strains during high-speed running: a longitudinal study including clinical and magnetic resonance imaging findings. Am J Sports Med 2007;35:197-206.

32. Elliott MC, Zarins B, Powell JW, et al. Hamstring muscle strains in professional football players: a 10-year review. Am J Sports Med 2011;39:843-50.

33. Garrett WE Jr. Muscle strain injuries: clinical and basic aspects. Med Sci Sports Exerc 1990;22:436-43

34. Jönhagen S, Németh G, Eriksson E. Hamstring injuries in sprinters. The role of concentric and eccentric hamstring muscle strength and flexibility. Am J Sports Med 1994:22:262-6.

35. Hawkins RD, Fuller CW. A prospective epidemiological study of injuries in four English professional football clubs. Br J Sports Med 1999;33:196-203.

36. Greig M, Siegler JC. Soccer-specific fatigue and eccentric hamstrings muscle strength. J Athl Train 2009;44:180-4.

37. Pinniger GJ, Steele JR, Groeller H. Does fatigue induced by repeated dynamic efforts affect hamstring muscle function? Med Sci Sports Exerc 2000;32:647-53.

38. Arnason A, Sigurdsson SB, Gudmundsson A, et al. Risk factors for injuries in football. Am J Sports Med 2004;32:5S-16S.

39. Gabbe BJ, Bennell KL, Finch CF, et al. Predictors of hamstring injury at the elite level of Australian football. Scand J Med Sci Sports 2006;16:7-13.

40. Garrett WE Jr. Muscle strain injuries. Am J Sports Med 1996;24:S2-8

41. Hägglund $\mathbf{M}$, Waldén $\mathbf{M}$, Ekstrand J. Previous injury as a risk factor for injury in elite football: a prospective study over two consecutive seasons. Br J Sports Med 2006;40:767-72. 